\title{
Investigation on Numerical Modeling of Water Vapour Condensation from a Flue Gas with High $\mathrm{CO}_{2}$ Content
}

\author{
Hamid Nabati \\ School of Sustainable Development of Society and Technology, Mälardalen University, \\ Västerås, Sweden \\ E-mail: hamid.nabati@gmail.com \\ Received February 2, 2011; revised April 7, 2011; accepted April 11, 2011
}

\begin{abstract}
In this paper, condensation of water vapor from a mixture of $\mathrm{CO}_{2} / \mathrm{H}_{2} \mathrm{O}$ is studied numerically. To simplify the study and focus on the physical model, a simple vertical plate was chosen. Two condensation models are developed and numerical approach is considered to implement these models. The main objective in the current paper was to study the capability of numerical modeling in prediction of complex process. Results showed that developed condensation models in combination with numerical approach can predict the trends in condensation behavior of binary mixture very well. Results from this study can be developed further to be used in design of condensers which are suitable for oxy-fuel power plants.
\end{abstract}

Keywords: Condensation, Two Phase Flow, Numerical Modeling, $\mathrm{CO}_{2}$ Capturing, Oxy-Fuel Power Plants

\section{Introduction}

Oxy-fuel power plants are one of the recently promising processes for clean energy production with $\mathrm{CO}_{2}$ capturing and condensers for separation of water vapour from flue gas are essential components in these new proposed power plants.

As the combustion process in the oxy-fuel power plants is performed with fuel and pure oxygen, the resulting flue gas consists mostly of $\mathrm{H}_{2} \mathrm{O}$ and $\mathrm{CO}_{2}$. The water vapour separation process from the flue gas impacts the thermal efficiency of the plant and the operational cost; thus the precise design of such $\mathrm{CO}_{2} / \mathrm{H}_{2} \mathrm{O}$ condenser systems is a vital demand in the industry [1-3]. Currently there are commercialized condensers in the market that most of them are installed for separation of air and water or for condensation of nearly pure water steams and thus far the condensers for separation of water vapor and $\mathrm{CO}_{2}$ are not off the shelf products yet. Considering the specific characteristics of such condensers for application in the $\mathrm{CO}_{2} / \mathrm{H}_{2} \mathrm{O}$ separation, makes them as special process heat exchangers in the industry. Despite of wide referring to this kind of condenser in different proposed Oxy fuel cycles, the required design data are not available yet and there is a demand for more studies to achieve the desired efficiency for $\mathrm{CO}_{2}$ capturing and steam separation and basic studies on condensa- tion of water vapour from a flue gas with high $\mathrm{CO}_{2}$ concentration could provide such useful technical data for designers.

Naturally, condensation happens whenever the vapour temperature is decreased by cooling until it reaches the saturation temperature $T_{\text {sat }}$ at the operational pressure and usually this takes place when vapor is brought into contact with a solid surface whose temperature $T_{s}$ is less than saturation temperature of the vapor. However condensation can also occur in a gas or on the interface of a liquid and a gas. When condensation occurs in a gas, the liquid droplets usually suspend in the gas. As it is more common in the industry to operate and control surface contacts condensers and also based on what is shown for oxy-fuel $\mathrm{CO}_{2}$ capturing, in the current study the condensation on solid surfaces with focus on film condensation is considered.

It is a common practice in the literatures to accept film condensation in heat exchanger design [4-6]. In this process, the condensate forms a liquid film is formed on the solid surface. This liquid film slips down under the influence of gravity. The thickness of the liquid film increases gradually with more vapors condensation on the film in the flow direction. Liquid covers the surface and eventually a liquid film takes place between vapour and solid surface. This liquid film resists against heat transfer flow. It means that released heat from vapour condensa- 
tion at the vapour-liquid interface must transmit through this layer before it approaches the cooling solid surface.

Moreover, the presence of even a small quantity of non-condensable gas significantly affects the heat transfer resistance in the region of the vapour-liquid interface. Experimental studies show that the non-condensable gases existence in the mixture has an unfavorable consequence on condensation process $[7,8]$. As an example, the presence of less than 1 percent (by mass) of air in steam decreases the condensation heat transfer coefficient more than half [4]. Vapour carries the non-condensable gas towards the vapour-liquid interface and it accumulates there. Thus special consideration should be applied when condensation from $\mathrm{CO}_{2} / \mathrm{H}_{2} \mathrm{O}$ mixture is studied. In this case a large portion of gas stream is occupied by $\mathrm{CO}_{2}$ which is a non-condensable gas in the normal condition. This is one of the cases that are referred as multi-component $(n>2)$ mixture condensation where $\mathrm{n}$ represents the number of components. The $\mathrm{CO}_{2} / \mathrm{H}_{2} \mathrm{O}$ flue gas is a binary $(n=2)$ mixture that its phase equilibrium characteristics is important in flue gas condenser design and operation.

Condensation of water vapor from $\mathrm{CO}_{2} / \mathrm{H}_{2} \mathrm{O}$ flue gas mixture on a vertical smooth surface is shown schematically in the Figure 1.

Referring to this figure, the condensation behavior can be explained as the following:

When water vapor starts to condense, only the noncondensable gas part in the mixture remains in the vicinity of the interface surface. This gas layer acts as an obstacle between vapor and surface, and makes it difficult for the vapor to penetrate and reach the surface. Consequently, the efficiency of the condensation process is reduced.

There are limited works about surface condensation which have been performed either experimentally or numerically. Recently, some studies have been performed on vapour condensation from mixture of noncondensable gases and steam. However, nowadays, the main idea is to use available tools (like numerical methods) to develop robust and reliable methods which can be used to simulate the heat and mass transfer in condensation process.

Three main categories of condensation models are available: models with experimental correlations, models using Nusselt theory (based on heat and mass transfer analogy) and mechanistic models based on the boundary layer equations [9]. The main advantage of the first group models is their simplicity and therefore they can be easily adopted for numerical modeling. Also they can be used for initial verification of CFD condensation modeling. However they are bounded to a very limited set of data. The second group models are also suitable to

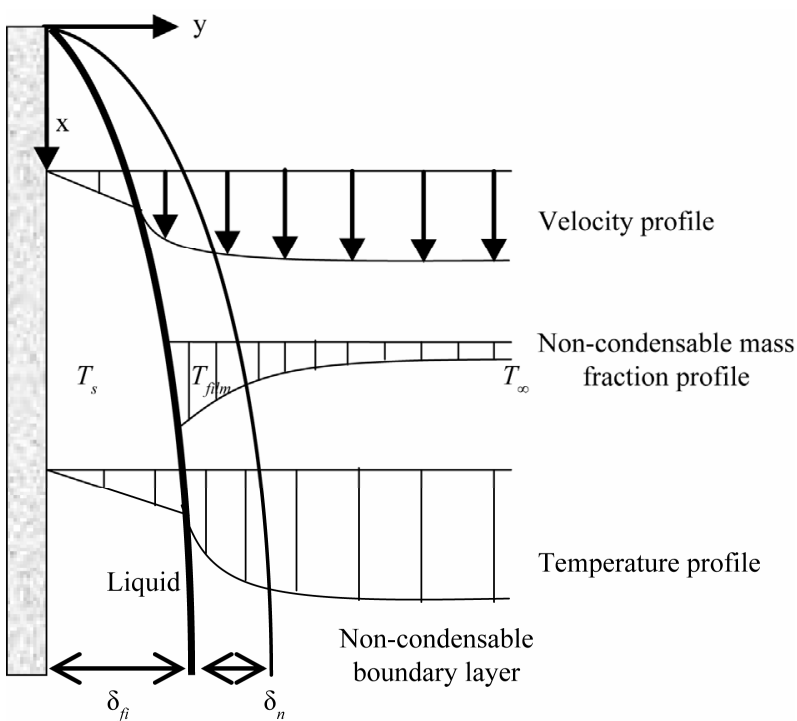

Figure 1. Water vapour condensation on a smooth vertical plane from a mixture containing non-condensable gas.

be implemented in the numerical simulation and they give more realistic results. The last group models are consistent with the numerical treatment of governing equations. But at the moment, implementation of such models requires high expenses because of their high degree of complexity. These are the best models that probably will be implemented in high accuracy CFD codes in future. This work evaluates two condensation models through a numerical simulation and propose the optimum model based on available two-phase flow models and apply it in a numerical scheme with the help of Fluent $^{\circ}$ software to study water vapour condensation from a mixture containing mainly $\mathrm{H}_{2} \mathrm{O}$ and $\mathrm{CO}_{2}$. Also effect of fin installation on the condensation surface is partly studied.

\section{Physical Model for Binary System Condensation}

As it was stated before, if any quantity of non-condensable gas exists in the mixture, there would be major effects on the heat and mass transfer resistance in the liquid-vapour interface. The non-condensable gas is carried towards the interface and accumulates there. This accumulation causes the partial pressure of gas at the interface became greater than its partial pressure in the binary mixture. This effect produces a driving force for non-condensable gas to diffuse again toward the bulk. This diffusive motion is contrary to water vapour diffusion toward liquid-vapour interface. Also when the vapor which is mixed with a non-condensable gas is condensing, only the non-condensable gas remains in the vicinity of the liquid-gas surface. This gas layer forms a resisting wall 
between condensing liquid and vapor and makes it hard for the vapor to contact with the surface. Therefore vapor should diffuse through this layer first before reaching the surface. These effects reduce the condensation process efficiency. These conditions are worse for the $\mathrm{CO}_{2} / \mathrm{H}_{2} \mathrm{O}$ condenser, where the concentration of $\mathrm{CO}_{2}$ is much higher than water vapour. The accumulation of $\mathrm{CO}_{2}$ in the vicinity of condensation layer makes a barrier to remaining water vapour in the flue gas stream and decreases the effectiveness of condensation process.

In the mixture of $\mathrm{CO}_{2} / \mathrm{H}_{2} \mathrm{O}$, the partial pressure $P_{A}$, of component $\mathrm{H}_{2} \mathrm{O}$ is that pressure which would be exerted by $\mathrm{H}_{2} \mathrm{O}$ alone in the mixture appropriate to the concentration of $\mathrm{H}_{2} \mathrm{O}$ in the flue gas at the same temperature. Here A represents $\mathrm{H}_{2} \mathrm{O}$ to simplify the proceeding equations. Since $P=\Sigma P_{A}$, then the partial pressure, $P_{A}$, is proportional to the mole fraction of $\mathrm{H}_{2} \mathrm{O}$ in the vapour phase.

$$
P_{A}=x_{A} \cdot P_{A}^{s a t}
$$

The most known correlation that is used to relate the partial pressure in the vapour phase to the concentration of component A in the liquid phase is the Rault's law. This law states that the partial pressure $P_{A}$ is related to the mole fraction $x_{A}$ and saturation pressure of pure component $A$ at the same temperature:

$$
P_{A}=x_{A}^{\prime} \cdot P_{A}^{\text {sat }}
$$

where $x_{A}$ represents mole fraction of component $\mathrm{A}$ in the liquid phase. During mass transfer process, water vapour travels from high concentration region to region where it has a low concentration. Just as thermal energy diffuses from region of high temperature to low temperature region (following the temperature gradient), the mass transfer follows the concentration gradient. Fick's law of diffusion represents that diffusion mass flux of any species in a multi-components stream has direct proportion to the species concentration gradient. This law can be expressed as:

$$
\boldsymbol{J}_{i}=-\rho \cdot D_{i m} \cdot \frac{\partial m_{i}}{\partial m}
$$

$\boldsymbol{J}_{i}$ is the total mass flux of species $i$ and gets the unit of $\left(\mathrm{kg} / \mathrm{m}^{2} \cdot \mathrm{s}\right)$. Effective diffusivity, $D_{i m}$ is an indicator of diffusion intensity of species $i$ into a mixture. Diffusivity coefficient is a function of composition, temperature and pressure and for gases is typically on the order of $10^{-5}$ near the room temperature. The Chapman-Enskog correlation is one of the known formulas which is based on kinetic theory and takes into account all the molecular effects precisely [9]. The correlation is:

$$
D_{A B}=\frac{\left(1.8583 \times 10^{-7}\right) \cdot T^{\frac{3}{2}}}{p \cdot \sigma_{A B}^{2} \cdot \Omega_{D}} \cdot \sqrt{\frac{1}{M_{A}}+\frac{1}{M_{B}}}
$$

$\sigma_{A B}$ is the average molecular diameter in $\AA$ and is equal to $\left(\sigma_{A}+\sigma_{B}\right) / 2 . M_{A}$ and $M_{B}$ are molecular weight of components $A$ and $B . \Omega_{D}$ can be obtained from available correlations in literatures [4,10,11]. Table 1 shows the required data for diffusivity calculation.

Considering the steady state behavior at the all location in the flow field and referring to Figure 1, the energy balance implies that the heat transfer from the flue gas to the condensation film plus the latent heat of condensation should be equal to the heat which is passing through the condensation film. As the temperature level is the place that condenser is going to be used is something about $100^{\circ} \mathrm{C}$ (more or less), the radiation from flue gas to the film can be neglected.

The first attempt to analyze the film condensation process was done by Nusselt with some simplifying assumptions like laminar film flow, stationary vapour and conduction heat transfer trough the film. Based on the analysis, he proposed the following correlation for the mean value of heat transfer coefficient over the whole vertical surface [12]:

$$
h_{\text {film }}=0.943\left[\frac{g \cdot \rho_{f}\left(\rho_{f}-\rho_{g}\right) h_{f g} \cdot k_{f}^{3}}{\mu_{f}\left(T_{f i l m}-T_{S}\right) \cdot L}\right]^{\frac{1}{4}}
$$

A number of attempts have made to improve the Nusselt theory and modify it to suit the real process. The condensate in a real condensation process always is cooled down further to a temperature which is less than saturation temperature and higher than the cooling wall temperature. Rohsenow [13] showed that this effect can be accounted by using modified latent heat defined as:

For the water vapour content in the flue gas, there is superheat state and the vapor should be cooled down to $T_{\text {sat }}$ before the condensation occurs. In this case the modified latent heat can be written as:

$$
\begin{aligned}
h_{f g}^{* *}= & h_{f g}\left(1+\frac{0.63 C_{P, f i l m}\left(T_{f i l m}-T_{S}\right)}{h_{f g}}\right. \\
& \left.+\frac{C_{P, \infty}\left(T_{\infty}-T_{s a t}\right)}{h_{f g}}\right)
\end{aligned}
$$

\begin{tabular}{|c|c|c|c|}
\hline Species & $\varepsilon / k_{B}(K)$ & $\sigma(\AA)$ & $M(\mathrm{~kg} / \mathrm{kmol})$ \\
\hline Air & 78.6 & 3.711 & 28.96 \\
\hline $\mathrm{H}_{2} \mathrm{O}$ & 363 & 2.655 & 18.02 \\
\hline $\mathrm{CO}_{2}$ & 195.2 & 3.941 & 44.01 \\
\hline
\end{tabular}

Considering the definition for modified latent heat, the convective heat transfer coefficient through the condensing film $\left(h_{\text {film }}\right)$ can be written as [4]:

Table 1. Required data for diffusivity calculation [10]. 


$$
h_{f i l m}=0.943\left[\frac{g \cdot \rho_{f}\left(\rho_{f}-\rho_{g}\right) h_{f g}^{* *} \cdot k_{f}^{3}}{\mu_{f}\left(T_{s a t}-T_{S}\right) \cdot L}\right]^{\frac{1}{4}}
$$

All the liquid properties should be calculated at average temperature $\left(T_{\text {sat }}+T_{s}\right) / 2$.

The heat transfer from flue gas to interface layer between flue gas and condensing film consists of two parts: firstly, heat which passes the diffusion layer directly and reach to the interface (sensible heat) and secondly the latent heat of the vapour which reaches the interface and condenses. With an assumption that the liquid-vapor interface has a temperature between saturation and surface temperatures and also considering the constant temperature for the liquid film interface, the energy balance equation is written as following:

$$
\begin{aligned}
& q_{\text {tot }}=q_{\text {film }}=q_{\text {conv }}+q_{\text {condens }} \\
& \text { or } \\
& \begin{aligned}
h_{\text {tot }} \times\left(T_{\infty}-T_{s}\right) & =h_{f} \times\left(T_{f}-T_{s}\right) \\
& =h_{\infty} \times\left(T_{\infty}-T_{f}\right)+h_{\text {cond }} \times\left(T_{\infty}-T_{f}\right)
\end{aligned}
\end{aligned}
$$

And condensation film flow rate is given by:

$$
\dot{m}_{\text {cond }} \cdot h_{f g}^{* *}=h_{f} A_{s}\left(T_{f}-T_{s}\right)
$$

$h_{\infty}$ in (9) represents the convective heat transfer coefficient between flue gas and condensation film considering the mass transfer and is calculated in the CFD code automatically using wall functions. So it is not explained here and details can be found in the user guide [13]. The last coefficient in (9) is the most challenging part in condensation modeling. In the current paper, two different condensation models are implemented and compared together which are explained in the following sections.

\subsection{Model I: Based on Nusselt Theory}

The first condensation model is based on Nusselt theory [12] and is simple to be implemented in the numerical code Firstly, the heat transfer in a pure vapour atmosphere using the saturation condition is calculated and then effect of non-condensable gas is introduced by a degradation factor. The following formula is derived with this methodology:

$$
q_{\text {cond }}=f_{n c} \cdot\left[\frac{g \cdot \rho_{f}\left(\rho_{f}-\rho_{g}\right) h_{f g} \cdot k_{1}^{3}}{\mu_{f} \cdot\left(T_{s a t}-T_{f}\right) \cdot L}\right]^{\frac{1}{4}}\left(T_{s a t}-T_{f}\right)
$$

The degradation factor is calculated based on experimental works and here the following correlation is implemented [15]:

$$
\begin{aligned}
f_{n c}= & {\left[1-0.946 y_{n c}+4.989 y_{n c}^{2}-4.135 y_{n c}^{3}\right] } \\
& \times\left[\frac{1-y_{n c}}{1+15.48 y_{n c}}\right]
\end{aligned}
$$

The condensation flow rate is calculated using the modified latent heat, $h_{f g}^{* *}$ :

$$
\dot{m}_{\text {cond }} \cdot h_{f g}^{* *}=q_{\text {cond }}
$$

\subsection{Model II: Based on Diffusion Boundary Layer Theory}

This model is originally developed by Peterson [15]. The condensation heat transfer coefficient $\left(h_{\text {condens }}\right)$ is given by following correlation [4]:

$$
h_{\text {cond }}=\frac{S h_{L}}{L} \cdot\left(\frac{D_{A B} \cdot h_{f g}^{2} \cdot C_{p, g} \cdot M_{v}^{2}}{R_{v} \cdot T_{f} \cdot T_{\infty}}\right) \cdot \phi
$$

$S h_{L}$ is the average Sherwood number for the whole condensing plate which is given by [4]:

$$
S h_{L}=0.664 R e_{L}^{\frac{1}{2}} \cdot S c^{\frac{1}{3}}
$$

$\phi$ issteam and non-condensable gas concentration in the vicinity of interface and defined as [4]:

$$
\phi=\frac{x_{n c, \text { mean }}}{x_{\text {steam, mean }}}=-\frac{\ln \left(\frac{1-x_{n c, \text { mean }}}{1-x_{n c, \text { interface }}}\right)}{\ln \left(\frac{x_{n c, \text { mean }}}{x_{n c, \text { interface }}}\right)}
$$

\section{Numerical Approach}

\subsection{Governing Equations}

The governing equations for conversation of mass, momentum and energy given by [17] can be formulated by using the tensor notation. The flue gas mixture and condensation layer are considered as Newtonian fluids. The Fluent ${ }^{\circ}$ CFD code has been employed to solve the process governing equations. Energy, momentum and continuity equations for each species are solved in a structured or unstructured mesh using finite volume method. Most of the following explanations on governing equations have been derived from available literatures [14], [17].

\subsubsection{Continuity Equation}

If conservation equation is applied to a species and then rearranged in a general form, the following equation is obtained: 


$$
\frac{\partial}{\partial t}\left(\rho y_{i}\right)+\nabla \cdot\left(\rho y_{i}\right)=-\nabla \cdot \boldsymbol{J}_{i}+S_{i}
$$

$S_{i}$ represents mass source term for species $i$ and calculated based on mixture unit volume. Diffusive flux for each species $\boldsymbol{J}_{i}$ was previously presented by (3).

$$
\frac{\partial}{\partial t}\left(\alpha_{q} \cdot \rho_{q}\right)+\nabla \cdot\left(\alpha_{q} \cdot \rho_{q} \cdot \boldsymbol{u}_{q}\right)=\sum_{p=1}^{n} \dot{m}_{p q}
$$

where $\alpha_{q}$ represents volume fraction of $q^{\text {th }}$ phase:

$$
\alpha=\frac{\text { Volume of the phase in a cell } / \text { domain }}{\text { Volume of the cell } / \text { domain }}
$$

\subsubsection{Momentum Equation}

This equation is based on second law of Newton and represents that for each fluid particle, rate of momentum change is equal to sum of all forces on that particle.

Transient term + Convection term $=$ Pressure force + Body force + Shear force + Inter-phase forces and momentum exchange + other external forces

Or in the mathematical form:

$$
\begin{aligned}
& \frac{\partial}{\partial t}\left(\alpha_{q} \cdot \rho_{q} \cdot \boldsymbol{u}_{q}\right)+\nabla \cdot\left(\alpha_{q} \cdot \rho_{q} \cdot \boldsymbol{u}_{q} \cdot \boldsymbol{u}_{q}\right) \\
& \quad=-\alpha_{q} \nabla p+\alpha_{q} \rho_{q} \boldsymbol{g}+\sum_{p=1}^{n}\left(R_{p q}+\dot{m}_{p q} \boldsymbol{u}_{q}\right)+\alpha_{q} \rho_{q} \boldsymbol{F}_{q}
\end{aligned}
$$

$\dot{m}_{p q}$ is the mass transfer rate from phase $q$ to phase $p$. The momentum equation can be simplified for different flows based on the flow conditions.

\subsubsection{Multiphase Species Transport Equation}

General multiphase species transport equation for species $i$ which belongs to mixture of the $q^{\text {th }}$ phase is expressed as following:

$$
\begin{aligned}
& \frac{\partial}{\partial t}\left(\alpha_{q} \cdot \rho_{q} \cdot y_{q}^{i}\right)+\nabla \cdot\left(\alpha_{q} \cdot \rho_{q} \cdot \boldsymbol{u}_{q} \cdot y_{q}^{i}\right) \\
& \quad=-\nabla \cdot \alpha_{q} \boldsymbol{J}_{q}^{i}+\alpha_{q} S_{i}+\sum_{p=1}^{n}\left(\dot{m}_{p^{i} q^{j}}-\dot{m}_{q^{j} p^{i}}\right)
\end{aligned}
$$

where the $y_{q}^{i}$ represents the mass fraction of the species $i$ in the qth phase and $S_{i}$ is the volumetric rate of mass increase (could be also a negative value) for component $i$.

\subsubsection{Energy Equation}

The energy conservation equation is based on enthalpy equations for all phases. This equation is representing in the following form [14]:

$$
\begin{aligned}
& \frac{\partial}{\partial t}\left(\alpha_{q} \cdot \rho_{q} \cdot h_{q}\right)+\nabla \cdot\left(\alpha_{q} \cdot \rho_{q} \cdot \boldsymbol{u}_{q} \cdot h_{q}\right)=-\alpha_{q} \frac{\partial p_{q}}{\partial t} \\
& +\nabla \cdot\left(\alpha_{q} \overline{\bar{\tau}}_{q} \nabla \boldsymbol{u}_{q}\right)-\nabla \boldsymbol{q}_{q}+S_{q}+\sum_{p=1}^{n}\left(Q_{p q}+\dot{m}_{p q} h_{p q}-\dot{m}_{q p} h_{q p}\right)
\end{aligned}
$$

Here $h_{q}$ is the specific enthalpy of the $q^{\text {th }}$ phase and $\overline{\bar{\tau}}_{q}$ is the phase stress-strain tensor. Explanations on other terms in energy equation can be found in [14].

\subsubsection{Mass Transfer Considerations}

In the Fluent $^{\circ}$, contributions due to mass transfer are added only to the momentum, species and energy equations and no source term is added to other scalars like turbulence [14]. More detail can be found in the Fluent ${ }^{\circ}$ website or user manuals. No general model exist for mass transfer and it depends on the case like evaporation, boiling or condensation, The UDF should be used to input the appropriate model for condensation and sink of mass is imposed into the continuity equation.

\subsection{Simulation Model}

Two 2D models were used to study the described water vapour condensation model, when mixture contains high $\mathrm{CO}_{2}$ concentration (Figure 2). First model is a simple vertical plate and the second one is a vertical plate with same dimension as the first one which is equipped with some fins.

The later model has been used to primary study how fins affect on condensation model output. Fins are considered as a simple rectangles attached to the cooling wall. Copper was selected as the material for fins. The generated meshes for both models are structured map element meshes. Meshes were generated several times to assure a mesh dependent solution. Also meshes were refined in the areas close to walls to get accurate results in the boundary layer section. Two adiabatic inlet and outlet sections were considered to ensure that the correct flow condition in the condensation zone was achieved.

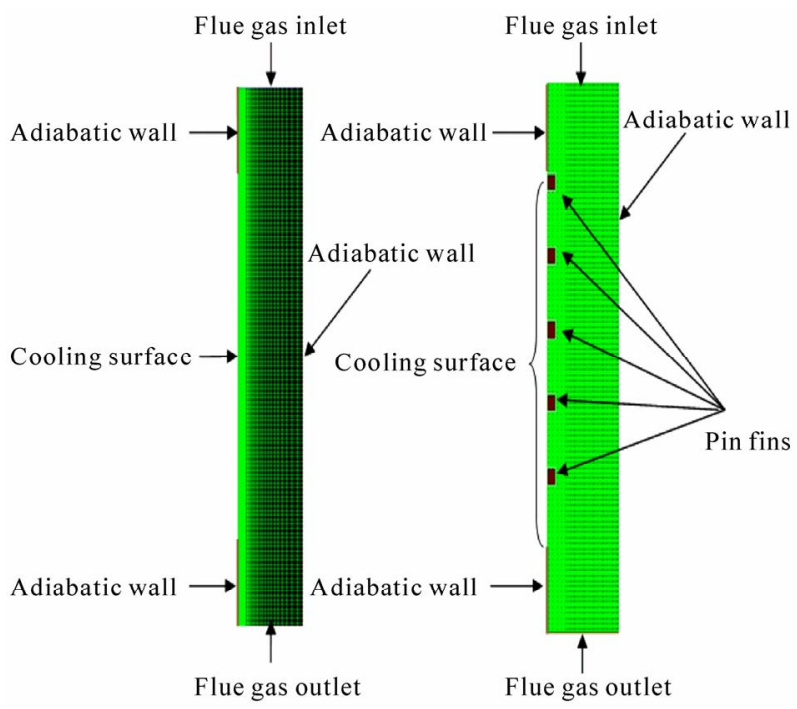

Figure 2. 2D models that are used for condensation study. 
For simulation start up, first the interface temperature is approximated and condensing film properties and heat transfer coefficient has been determined in first cells adjacent to the cooling wall. Condensation mass flow rate and heat flux are calculated then based on the equation that described in the former sections. Then the heat balance calculation is performed and new film interface temperature is calculated. This procedure continuous until the good agreement between old and new film interface is achieved.

\section{Investigated Cases}

Two main cases are considered: Simple flue gas channel and flue gas channel fitted with pin fins internally. In the first case, two condensation models are implemented and compared. The first model is based on Nusselt theory and the latter is based on diffusion boundary layer theory as described in section 2. Then based on this study, the selected condensation model is selected and implemented in the second case to study the effect of fins in thermo-hydraulic behavior of condensation process.

\section{Validity of Models}

First model was run with a binary mixture of air and water vapor. This is done first to validate the model and compare results with available correlation from literature $([8,18])$. Following correlation is proposed by Dehby $[8]$ :

$$
\begin{aligned}
h_{\text {condens }}= & \frac{L^{0.05}}{T_{\infty}-T_{S}} \cdot[(3.7+28.7 P) \\
& \left.-(2438+458.3 P) \cdot \log x_{n c}\right]
\end{aligned}
$$

Correlation is valid within these ranges:

$0.3 \mathrm{~m}<L<3.5 \mathrm{~m} ; 1.5 \mathrm{~atm} .<P_{t o t}<4.5 \mathrm{~atm}$.;

$10^{\circ} \mathrm{C}<\left(T_{\infty}-T_{S}\right)<50^{\circ} \mathrm{C}$

Heat transfer coefficient dependency on mass fraction of air at inlet is illustrated in Figure 3. As it is observed, the trend of both numerical condensation models is similar to the experimental correlation result. Even though experimental data and modeling results differ slightly, the presented diagram confirms that presented models are relatively capable to predict the condensation behavior of such condensers.

Some reasons for slight discrepancies between experimental and modeling results can be identified as followings:

1) Errors produced by measuring system (categorized as experimental errors).

2) Intrinsic numerical errors caused by computational procedures such as truncations (modeling errors).

3) Errors resulted from modeling simplification and assumptions (modeling errors).

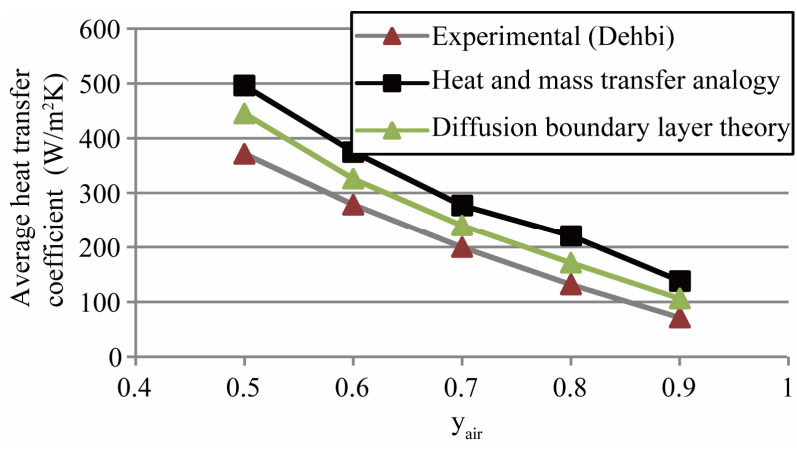

Figure 3. Verification of model validity (air/water vapour mixture).

To minimize the CFD modeling errors, mesh dependency of the solution was examined by solving the flow and temperature fields for different mesh configurations made of different cells. These profiles were compared in several sections for all configurations to be sure that the maximum difference in the flow field properties between the coarser and finer meshes are less than $1 \%$ and the final mesh lead to mesh-independent solutions. Based on these results, the flue gas mixture then changed from Air $/ \mathrm{H}_{2} \mathrm{O}$ to $\mathrm{CO}_{2} / \mathrm{H}_{2} \mathrm{O}$ and appropriate material properties supplied to the model to make it more suitable for Oxy-fuel process.

\section{Results and Discussion}

Presented results in the current section include output data obtained from different simulations. The modeling started with a validation of reference case to examine the condensation models and then it followed by a different case containing pin-fins. Results obtained for this model are presented in Figures 4 to 8. Several checks were performed in order to verify accuracy of the generated results. The contour plots for velocity, temperature and pressure were observed separately to confirm that the results satisfy the boundary conditions and also they are independent of grid size.

A comparison of two condensation model is presented in Figure 4. The relation between total heat transfer coefficient and $\mathrm{CO}_{2}$ mass fraction are illustrated here.

As the $\mathrm{CO}_{2}$ mass fraction increases, both models intend to give closer results. However the predicted results from the first condensation model (based on Nusselt theory (or heat and mass transfer analogy)) stand higher. Both model show that total heat transfer decreases rapidly with any increase in $\mathrm{CO}_{2}$ concentration. A rough conclusion from figure is that $1 \%$ increase in $\mathrm{CO}_{2}$ mass fraction decrease the heat transfer coefficient about $1 \%$.

Figure 5 illustrates prediction of condensation rate. The trend of condensation rate is consistent with theory. As the $\mathrm{CO}_{2}$ mass fraction increases, the condensation 


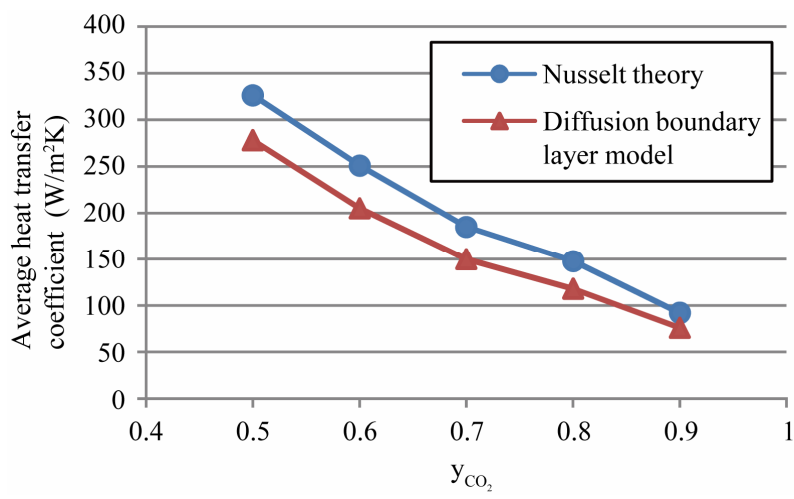

Figure 4. Comparison of two condensing models in mean heat transfer coefficient prediction $\left(\mathrm{CO}_{2} / \mathrm{H}_{2} \mathrm{O}\right.$ mixture).

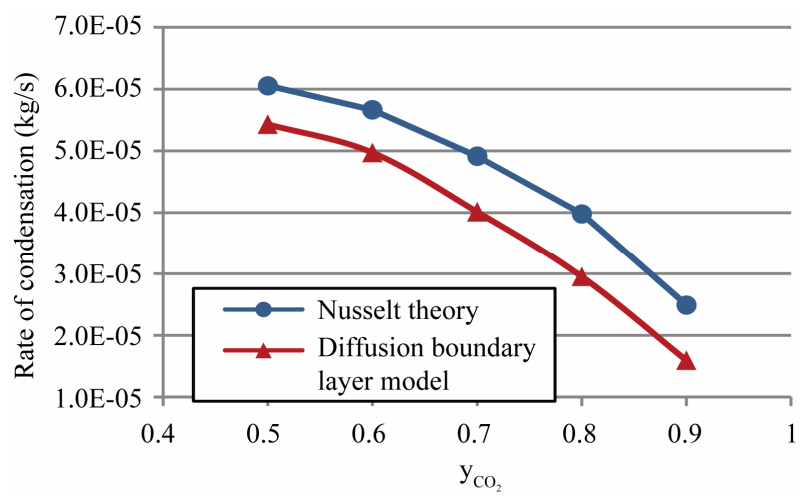

Figure 5. Comparison of condensation rate for two condensation models.

rate decreases more sharply. The reason is that firstly there is less water content in the flow gas and secondly the diffusion of water vapour toward the cooling surface became more difficult.

Results also showed that average heat transfer coefficient is more sensitive to inlet velocity at low speeds. Figure 6 shows the results that are obtained with model based on diffusion boundary layer theory. It can be seen that at velocities more than $1.5 \mathrm{~m} / \mathrm{s}$, the velocity effects is negligible. However, when the $\mathrm{CO}_{2}$ mass fraction is lower at the inlet, velocity can be an affecting parameter as well. The trend was found to be same for lower $\mathrm{CO}_{2}$ fractions.

Effect of flue gas inlet temperature on mean heat transfer coefficient is depicted in Figure 7. Also here for higher inlet temperatures, rate of heat transfer coefficient change is less. It is natural, as water vapour reach to saturation temperature with less heat removal. Subsequently the rate of condensation would be higher at lower inlet temperature.

Second case that was considered in this study was a vertical plate which was equipped with some pin fins. Figure 8 shows the comparison of total heat transfer coefficient in the simple condensing plate and surface

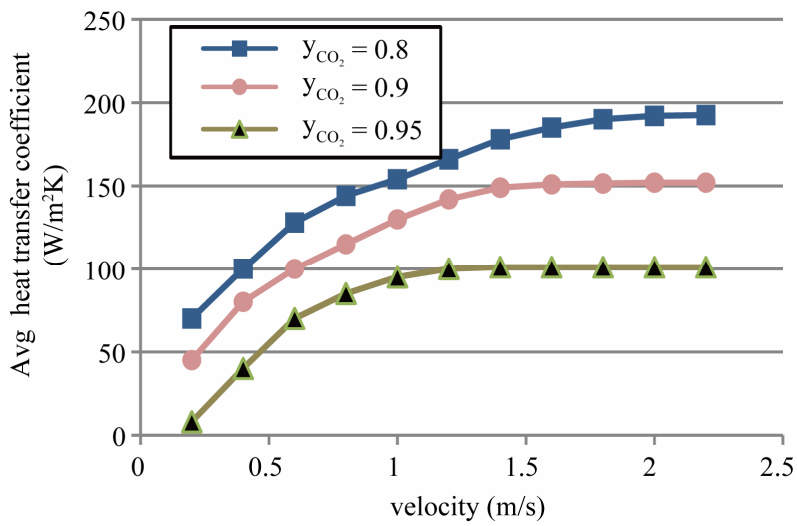

Figure 6. Average heat transfer coefficient vs inlet flue gas.

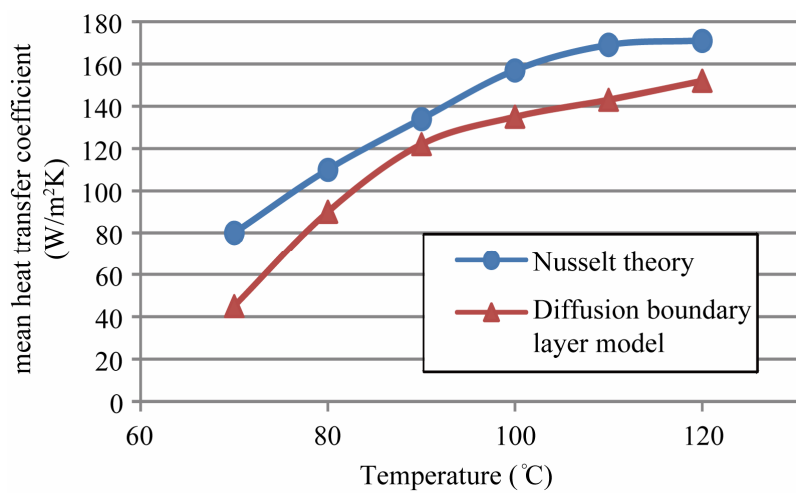

Figure 7. Relation between inlet temperature and total heat transfer coefficient.

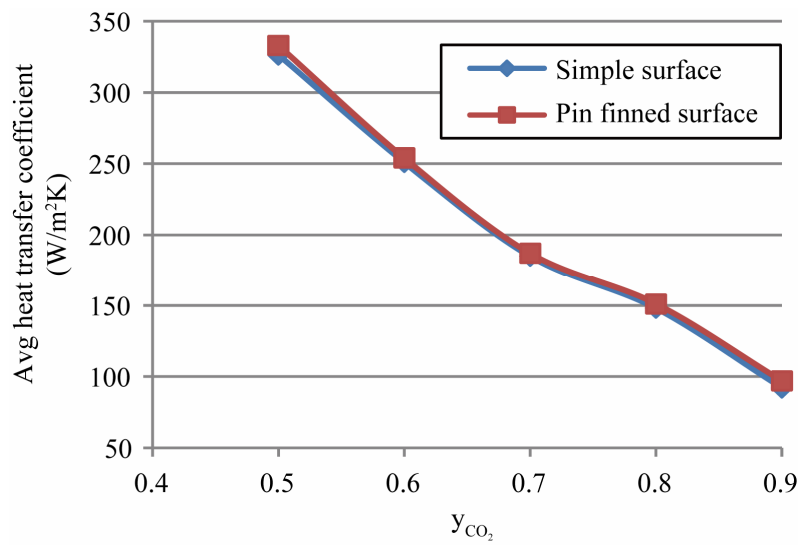

Figure 8. Comparison of total heat transfer coefficient between simple case and pin-finned surface

with pin fins. Figure shows that the difference in coefficient values is negligible. It means that models that are developed here are not really accurate to predict the exact heat transfer coefficient in more complicate geometries. The reason is that the model just look into the cell adjacent to wall and the geometry is not accounted at all. Especially the correlations that were implemented are developed for vertical case and some surfaces of pins are 
horizontal.

\section{Conclusions}

Simulating results have been presented for two condensation models and two different geometries. The physics of the problem and the heat transfer characteristics have been discussed for these models. The aim was to evaluate numerical modeling capabilities to predict water vapour condensation from a flue gas that contains high concentration of $\mathrm{CO}_{2}$. The results are summarized as followings:

1) Both models are capable to predict the trends in condensation process. However, the model based on boundary layer theory shows closer value to experimental correlation. The effect of the $\mathrm{CO}_{2}$ presence in the flue gas as a non-condensable gas was predicted correctly by both models.

2) Heat transfer coefficient decreases as a consequence of the increase in $\mathrm{CO}_{2}$ mass fraction for constant wall temperature as a result of the higher resistance to diffuse from the flue gas bulk to the boundary layer.

3) The total heat transfer rate depends on inlet velocity and temperature. However at higher inlet temperatures and velocities the sensitivity to these parameters decreases.

4) Heat transfer coefficient was estimated by calculating the interface temperature. However, it was found that it is possible to get approximately same results by assuming this temperature equal to wall temperature. This assumption facilitates the numerical efforts.

5) A brief description of the technical approach that was implemented for current study is:

Modeling surface contact condensers with Fluent ${ }^{\circ}$ requires the Eulerian model. This Eulerian multiphase model is an advanced model of Fluent and requires quite a bit of experience to handle. In addition, modification of these model to suit condensation process, which itself is a very complex process, would require both, good understanding of the physical process and good knowledge of model inside the Fluent. The accurateness of the numerical modeling results is determined by the empirical correlations specified to model the condensation process. In the industry, there is a practice to model the process with some correlations available in the open literature and then tweak various parameters to results which are close to the experimental results. Such a tuning is necessary in numerical modeling as well for most of the cases, as the general correlations may not yield accurate results for a specific set up. It is advisable that designing a condenser just based on Numerical results may be a difficult and expensive task.

\section{Acknowledgements}

Fluent Inc.'S solver capabilities are highly appreciated and I hereby knowledge use of it in the current paper.

\section{References}

[1] K. Andersson, "Combustion Tests and Modeling of the Oxy-Fuel Process-An Overview of R\&d Activities at Chalmers University," 2nd Oxy-Combustion Workshop at Windsor, CT, USA, 2007.

[2] M. B. Wilkinson and J. C. Boden, " $\mathrm{CO}_{2}$ Capture via Oxyfuel Firing: Optimization of a Retrofit Design Concept for a Refinery Power Station Boiler," 1st National Conference on Carbon Sequestration, Washington DC, 2001.

[3] Vattenfall, "Vattenfall's Project on CCS-Oxyfuel Combustion," 2009.

http://www.vattenfall.com/en/ccs/oxyfuel-combustion.ht $\underline{\mathrm{m}}$.

[4] Y. A. Cengel, "Heat Transfer: A Practical Approach," 2nd Edition, McGraw-Hil Higher Education, Dubuque, 2003.

[5] R. K. Shah and D. P. Sekulic, "Fundamentals of Heat Exchanger Design," John Wiley \& Sons, New Jersey, 2003. doi: $10.1002 / 9780470172605$

[6] G. F. Hewitt, "Hemisphere Handbook of Heat Exchanger Design," Hemisphere Publishing Corporation, Bristol, 1990.

[7] K. Karkoszka, "Mechanistic Modeling of Water Vapour Condensation in Presence of Non-Condensable Gases," Ph.D. Thesis, School of Engineering Sciences, Department of Physics, KTH. Stockholm, 2007.

[8] A. Dehbi and S. Guentay, "A Model for the Performance of a Vertical Tube Condenser in the Presence of Non-Condensable Gases," Proceeding of International Topical Meeting on Nuclear Reactor Thermal-Hydraulics, Vol. 177, No. 7, 1997, pp. 41-52. doi:10.1016/S0029-5493(97)00184-2

[9] J. M. Martín-Valdepeñas et al., "Comparison of Film Condensation Models in Presence of Non-Condensable Gases Implemented in a CFD Code," Heat and Mass Transfer, Vol. 41, No. 11, 2005, pp. 961-976. doi:10.1007/s00231-004-0606-5

[10] J. H. Lienhard IV and J. H. Lienhard V, "A Heat Transfer Textbook," 3rd Edition, Phlogiston Press, Cambridge, 2005 .

[11] I. Mamoru and H. Takashi, "Thermo-Fluid Dynamics of Two-Phase Flow," Springer, New York, 2006.

[12] J. G. Collier, "Convective Boiling and Condensation," McGraw-Hill Co., New York, 1980.

[13] W. M. Rohsenow, "Heat Transfer and Temperature Distribution in Laminar Film Condensation," Heat Transfer Journal, Vol. 78, 1956, pp. 1645-1648.

[14] Fluent 6.2 User Guide, 2005.

[15] M. H. Kim and M. L. Corradini, "Modeling of Condensation Heat Transfer in a Reactor Containment," Nuclear 
Engineering and Design, Vol. 118, No. 2, 1990, pp. 193-212. doi:10.1016/0029-5493(90)90057-5

[16] P. F. Peterson, V. E. Schrock and T. Kageyama, "Diffusion Layer Theory for Turbulent Vapor Condensation with Non-Condensable Gases," Journal of Heat Transfer, Vol. 115, No. 4, 1992, pp. 998-1003. doi: $10.1115 / 1.2911397$

[17] H. Versteeg and W. Malalasekra, "An Introduction to
Computational Fluid Dynamics: The Finite Volume Method," 2nd Edition, Pearson Education, New Jersey, 2007.

[18] A. A. Dehbi, M. W. Golay and M. S. Kazimi, "Condensation Experiments in Steam-Air Mixtures under Turbulent Natural Convection," National Conference of Heat Transfer, Vol. 87, No. 283, 1991, pp. 19-28.

\section{Nomenclature}

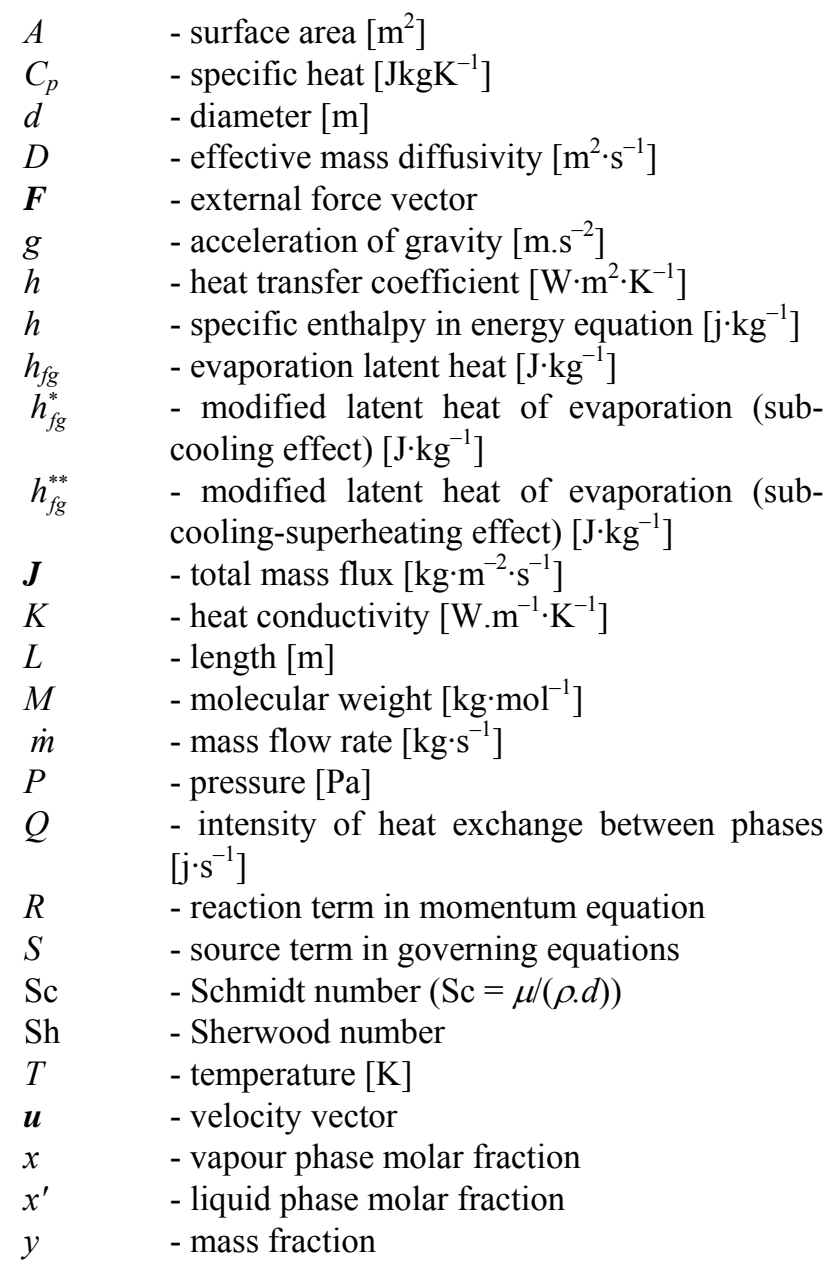

\section{Greek symbols}

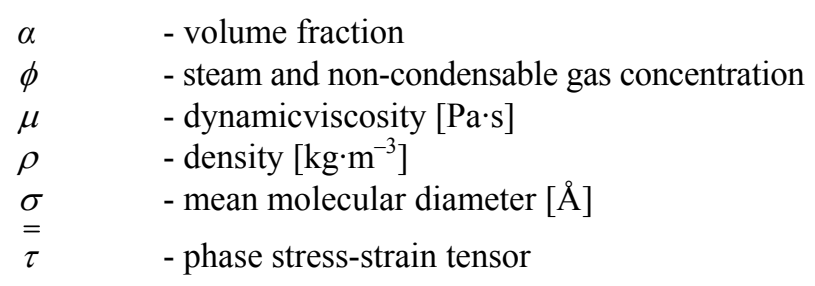

\section{Subscripts}

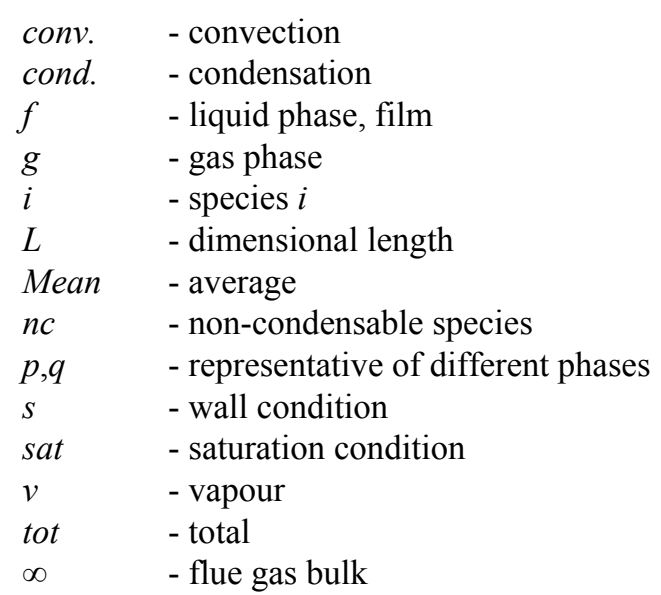

\section{Superscripts}

$\begin{array}{ll}\text { ave } & \text { - averaged } \\ i & \text { - species }\end{array}$

